\title{
nueva pintura a base de caucho sintéfico para mampostería de ladrillos
}

(Une nouvelle peinture pour maçonnerie, a base de caoutchouc synthétique)

EDYPORIAL

De: «Journal de la Construction de la suisse Romandew, año $\mathbf{X X X}^{\mathrm{a}}$, núm. 1, enero 195\%, pág. 29

Las investigaciones realizadas durante estos íltimos años han puesto de maniflesto, de una manera indiscutible, que si las mamposterias de ladrillos se recubren con una capa de pintura totalmente impermeable, existe el peligro de que queden destruidas bajo la acción de la humedad encerrada en ellas, sobre todo cuando dicha humedad se hiela en invierno. Por lo tanto, es necesario utilizar, s1 se quieren proteger las mamposterías, una pintura que sea suflcientemente impermeable para impedir que penetre la humedad desde el exterior, pero que sea, al mismo tiempo, bastante porosa para que la humedad encerrada en el interior pueda escapar.

La nueva pintura, Alkatite, preparada a base de caucho sintético, presenta esta propiedad. Además, tiene la ventaja de secarse rápidamente, dando una película mate, resistente a los álcalis; efectivamente, dicha pintura contiene un aglomerante insensible a los álcalis, asi como pigmentos que se escogen por su resistencia a la cal.

Para aplicar la pintura citada no es preciso llevar a cabo ningún tratamiento previo de la superficie en cuestión. Para su aplicación se utiliza brocha o pistola.

Esta pintura se puede emplear, tambłén, para la protecclón de las paredes internas de las piscinas.

S. F. S. 